\title{
Hosting a virtual conference in paediatric minimally invasive surgery: the experience of the 20th annual meeting of the British Association of Paediatric Endoscopic Surgeons
}

\author{
Alexander L. Macdonald ${ }^{1}$ (D) $\cdot$ Pankaj Mishra ${ }^{2} \cdot$ Anju Goyal $^{3} \cdot$ Helen Carter $^{4} \cdot$ Paul Charlesworth $^{5} \cdot$ Adil Aslam $^{6}$. \\ Abraham Cherian $^{7} \cdot$ Simon Clarke $^{8}$
}

Received: 23 March 2021 / Revised: 6 April 2021 / Accepted: 9 April 2021 / Published online: 19 April 2021

(c) The Author(s), under exclusive licence to Springer Nature Singapore Pte Ltd 2021

\begin{abstract}
The severe acute respiratory coronavirus-2 (SARS-CoV-2) pandemic necessitated a move to virtual meetings for the majority of medical specialty association conferences in 2020. We describe our experience with an entirely virtual meeting and conclude that a hybrid face to face/virtual solution represents the optimal format for future conferences in our specialty.
\end{abstract}

Keywords Minimally invasive surgery $\cdot$ Health technology $\cdot$ Virtual meetings $\cdot$ Telemedicine

\section{Introduction}

The severe acute respiratory coronavirus-2 (SARS-CoV-2) pandemic and consequent restrictions on travel and social gathering that were prevalent across the world in 2020 led to the majority of medical conferences becoming entirely virtual affairs. Subsequently, a tranche of literature pertaining to the technicalities and practicalities of holding these kind of events has arisen [1-5]. The critical question, however, is

Alexander L. Macdonald

alexander.macdonald@mac.com

1 BAPES Webmaster, Chelsea and Westminster Hospital, London, UK

2 BAPES Honorary Secretary, Evelina London Children's Hospital, London, UK

3 BAPES Treasurer, Royal Manchester Children's Hospital, Manchester, UK

4 BAPES Executive Committee Member, Leeds General Infirmary, Leeds, UK

5 BAPES Executive Committee Member, The Royal London Hospital, London, UK

6 BAPES Executive Committee Member, Addenbrookes Hospital, Cambridge, UK

7 BAPES President (2020-2022), Great Ormond Street Hospital, London, UK

8 BAPES President (2018-2020), Chelsea and Westminster Hospital, London, UK 'what is the future for the virtual medical conference when restrictions on travel and gathering recede?'. A satisfactory answer is invariably related to the nature of the meeting and the specialty itself. Therefore, there is merit to appraising the efficacy and future role of virtual meetings on a specialty by specialty basis.

In this article, we outline the path to the inaugural virtual meeting of the British Association of Paediatric Endoscopic Surgeons (BAPES) and contrast the experience of an entirely virtual meeting (London 2020) with that of an entirely face to face meeting (Leeds 2019) and put forward our views on the longer term role of virtual meetings in paediatric minimally invasive surgery.

\section{The path to a virtual BAPES}

The plans for the 20th annual meeting were originally conceived in 2018 and planned for November 2020 in London. With the onset of the severe acute respiratory coronavirus-2 (SARS-CoV-2) pandemic across the Spring/Summer of 2020 , plans were reconsidered in light of the restrictions on travel and social gathering.

\section{Deciding to go virtual}

The UK began a staged exit from its first national lockdown on May 10th and published a recovery strategy on May 11th. Alert to the possibility of long-suspected 
'winter surge' the BAPES executive considered a number of options (in line with the UK government guidance in place in the summer of 2020) which comprised:

1. A face to face meeting with restricted (50) attendees and appropriate social distancing.

2. A hybrid face to face meeting with restricted (50) attendees and appropriate social distancing combined with a live stream.

3. An entirely virtual meeting.

4. Postponing the meeting entirely until 2021.

The executive unanimously agreed that the third option was the most prudent given the high degree of uncertainly in the context of a continuously evolving set of restrictions. Subsequent to the decision to proceed with a virtual event cases began rising again in the autumn of 2020 and by October 12th the UK had entered a series of tiered regional lockdowns, with a second national lockdown following on what would have been the date of the first day of any face to face meeting-November 5 th.

\section{Choosing a platform}

When selecting a Webinar solution, the options can be divided into those that require the end user (the meeting attendee) to download a native client and those that run within a web browser. Native client solutions include Zoom (Zoom Video Communications Inc., San Jose CA) or GoToWebinar (LogMeIn, Boston MA) and browser based solutions include ON24 (ON24 Inc., San Francisco CA) or NTT (Nippon Telegraph and Telephone Corporation, Tokyo JP). Historically the preference has been for those solutions which do not require the additional friction of having to download a client but the pandemic-driven prevalence and consequent familiarity with client-based solutions (like Zoom in particular) in peoples professional and personal lives has perhaps removed this barrier.

Beyond the upfront cost, when choosing the best fit for your event considerations include: scalability (how many attendees do you require); reliability/stability (how willing are you to tolerate connection issues); accessibility (do you want to attendees to be able to join without downloading any additional software); customisability (do you have specific branding requirements) and analytics (do you require to collect data to better understand your audience for future event planning).

In the case of our event, we elected to use the NTT platform primarily as it was cost neutral for our organisation owing to our primary sponsor's existing partnership with NTT.

\section{BAPES 2019 vs BAPES 2020}

The 19th annual meeting of the BAPES was held in Leeds in November 2019 as an entirely face to face meeting. Table 1. Contrasts the breakdown of the 2019 face to face meeting with the 2020 virtual meeting.

\section{BAPES 2020 feedback}

$51 \%$ of attendees described themselves as paediatric surgeons, $39 \%$ as paediatric surgeons and urologists and $10 \%$ as only urologists. $41 \%$ were consultant equivalent grade surgeons and 68\% had a practice based in the UK. For $47 \%$ this was their first BAPES meeting.

With regard to the format $34 \%$ prefer face to face meetings, $14 \%$ prefer virtual, and $52 \%$ prefer a hybrid face to face/virtual meeting.

\section{The future for virtual meetings in our specialty}

At the time of writing, it is too early to draw assumptions regarding what restrictions our 2021 meeting may or may not operate under, but what does the BAPES meeting of 2022 and beyond look like?

As an organisation the BAPES is dedicated to the advancement of novel minimally invasive surgery and the annual meetings are a platform for novel and innovative techniques in our specialty. The use of modern video-conferencing technology to deliver events virtually is of course exceedingly innovative and the pandemic has led to aalbeit forced - step advancement in its deployment. For our particular specialty association it therefore fits culturally to embrace a digital future.

Clearly there were significant benefits derived from the virtual format -we witnessed a significant increase in the

Table 1 BAPES 2019 vs. BAPES 2020

\begin{tabular}{lll}
\hline & BAPES 2019 & BAPES 2020 \\
\hline Attendees & 110 & 254 \\
Length & 2 full days & $\times 23$ h sessions \\
Networking & $\begin{array}{l}\text { Conference dinner and } \\
\text { social evening }\end{array}$ & Nil \\
Keynotes & 2 & 2 \\
Scientific presentations & 73 & 22 \\
Special* sessions & 7 & 2 \\
Sponsor opportunities & Tables/booths & Website content \\
\hline
\end{tabular}

*Quizes, debates, panel discussions 
number of attendees and reached an international audience-and majority of attendees favoured the retention of a virtual component to future meetings.

However, there are a number of limitations - both generic and specific to our specialty-that current virtual solutions are yet to satisfactorily address.

- Time is limited both by the cost of bandwidth and the tolerance for attendees to sit in front of a computer which necessitates a very focused programme.

- Inter-professional social networking is limited and community spirit is lost.

- Audience engagement with events such as panel discussion session and debates is difficult to replicate.

- The options for sponsors to showcase their products is limited.

Ultimately, a medical specialty association conference is as much a meeting of a community of like-minded individuals as it is an educational event. Face to face inter-professional networking can, to an extent, be replicated virtually with 'break-out chat rooms'; however, the kind of spontaneous networking that comes from-for example-bumping into a colleague in the corridor or lunch queue is lost in the virtual alternative. As such current virtual solutions fall short of what is desired-particularly in a small niche specialty association where the fostering of a community spirit is a critical goal of the organisation.

In our particular circumstances-and we would imagine those of similar small sub-specialty associations-we would envisage the ideal being a combination of a face to face meeting to facilitate inter-professional networking with parallel virtual content to broaden access for trainees, allied health professionals, international surgeons and other groups who would not traditionally attend our meetings in significant numbers.

Delivering an effective 'hybrid' meeting is not without its own unique challenges such as requiring a venue with appropriate audio-visual and IT infrastructure for live-streaming, along with the difficulties of devising a funding model that ensures that the-likely much smaller-face to face meeting remains financially viable.
However, we remain confident that a hybrid event is practicable and that broadening access to the meeting - and consequently the audience for speakers-outweighs any immediate disadvantages for small specialty associations like ours.

Funding Nil.

\section{Declarations}

Conflict of interest The authors declare that there is no conflict of interest.

\section{References}

1. Antonoff MB, Mitzman B, Backhus L, Bradbury ST, Chatterjee S, Cooke DT, Crestanello J, Goldstone AB, Kim KM, Nguyen TC, Romano JC, Vaporciyan AA, Varghese TK Jr (2021) The society of thoracic surgeons (STS) virtual conference taskforce: recommendations for hosting a virtual surgical meeting. Ann Thorac Surg 111(1):16-23. https://doi.org/10.1016/j.athoracsur.2020.10. 008

2. Nelson BA, Lapen K, Schultz O, Nangachiveettil J, Braunstein SE, Fernandez C, Fields EC, Gunther JR, Jeans E, Jimenez RB, Kharofa JR, Laucis A, Yechieli RL, Gillespie EF, Golden DW (2020) The radiation oncology education collaborative study group 2020 spring symposium: is virtual the new reality? Int J Radiat Oncol Biol Phys S0360-3016(20):34691-34695. https:// doi.org/10.1016/j.ijrobp.2020.12.026

3. Ruiz-Barrera MA, Agudelo-Arrieta M, Aponte-Caballero R, Gutierrez-Gomez S, Ruiz-Cardozo MA, Madrinan-Navia H, VergaraGarcia D, Riveros-Castillo WM, Saavedra JM (2021) Developing a web-based congress: the 2020 international web-based neurosurgery congress method. World Neurosurg S1878-8750(21):0001800028. https://doi.org/10.1016/j.wneu.2020.12.174

4. Rubinger L, Gazendam A, Ekhtiari S, Nucci N, Payne A, Johal H, Khanduja V, Bhandari M (2020) Maximizing virtual meetings and conferences: a review of best practices. Int Orthop 44(8):14611466. https://doi.org/10.1007/s00264-020-04615-9

5. Porpiglia F, Checcucci E, Autorino R, Amparore D, Cooperberg MR, Ficarra V, Novara G (2020) Traditional and virtual congress meetings during the COVID-19 pandemic and the post-COVID-19 era: is it time to change the paradigm? Eur Urol 78(3):301-303. https://doi.org/10.1016/j.eururo.2020.04.018 